J. Dairy Sci. 98:3257-3273

http://dx.doi.org/10.3168/jds.2014-8587

(C) American Dairy Science Association ${ }^{\circledR}, 2015$.

\title{
Prediction of nutrient digestibility and energy concentrations in fresh grass using nutrient composition
}

\author{
S. Stergiadis, ${ }^{*}$ M. Allen, $\dagger$ X. J. Chen, ${ }^{*} \ddagger$ D. Wills, ${ }^{*}$ and T. Yan ${ }^{* 1}$ \\ *Sustainable Agri-Food Sciences Division, Agriculture Branch, Agri-Food and Biosciences Institute, Large Park, Hillsborough, \\ County Down, BT26 6DR, United Kingdom \\ †Finance and Corporate Affairs Division, Biometrics and Information Systems Branch, Agri-Food and Biosciences Institute, 18a Newforge Lane, \\ Belfast, County Antrim, BT9 5PX, United Kingdom \\ $\ddagger$ State Key Laboratory of Grassland Agro-Ecosystems, College of Pastoral Agriculture Science and Technology, Lanzhou University, \\ Lanzhou 730020, China
}

\begin{abstract}
Improved nutrient utilization efficiency is strongly related to enhanced economic performance and reduced environmental footprint of dairy farms. Pasture-based systems are widely used for dairy production in certain areas of the world, but prediction equations of fresh grass nutritive value (nutrient digestibility and energy concentrations) are limited. Equations to predict digestible energy (DE) and metabolizable energy (ME) used for grazing cattle have been either developed with cattle fed conserved forage and concentrate diets or sheep fed previously frozen grass, and the majority of them require measurements less commonly available to producers, such as nutrient digestibility. The aim of the present study was therefore to develop prediction equations more suitable to grazing cattle for nutrient digestibility and energy concentrations, which are routinely available at farm level by using grass nutrient contents as predictors. A study with 33 nonpregnant, nonlactating cows fed solely fresh-cut grass at maintenance energy level for $50 \mathrm{wk}$ was carried out over 3 consecutive grazing seasons. Freshly harvested grass of 3 cuts (primary growth and first and second regrowth), 9 fertilizer input levels, and contrasting stage of maturity ( 3 to 9 wk after harvest) was used, thus ensuring a wide representation of nutritional quality. As a result, a large variation existed in digestibility of dry matter (0.642-0.900) and digestible organic matter in dry matter (0.636-0.851) and in concentrations of $\mathrm{DE}(11.8-16.7 \mathrm{MJ} / \mathrm{kg}$ of dry matter) and ME (9.0-14.1 $\mathrm{MJ} / \mathrm{kg}$ of dry matter). Nutrient digestibilities and DE and $\mathrm{ME}$ concentrations were negatively related to grass neutral detergent fiber (NDF) and acid detergent fiber $(\mathrm{ADF})$ contents but positively related to nitrogen $(\mathrm{N})$,
\end{abstract}

Received July 9, 2014.

Accepted January 25, 2015.

${ }^{1}$ Corresponding author: tianhai.yan@afbini.gov.uk gross energy, and ether extract (EE) contents. For each predicted variable (nutrient digestibilities or energy concentrations), different combinations of predictors (grass chemical composition) were found to be significant and increase the explained variation. For example, relatively higher $\mathrm{R}^{2}$ values were found for prediction of $\mathrm{N}$ digestibility using $\mathrm{N}$ and $\mathrm{EE}$ as predictors; grossenergy digestibility using $\mathrm{EE}, \mathrm{NDF}, \mathrm{ADF}$, and ash; NDF, ADF, and organic matter digestibilities using $\mathrm{N}$, water-soluble carbohydrates, EE, and NDF; digestible organic matter in dry matter using water-soluble carbohydrates, EE, NDF, and ADF; DE concentration using gross energy, EE, NDF, ADF, and ash; and ME concentration using N, EE, ADF, and ash. Equations presented may allow a relatively quick and easy prediction of grass quality and, hence, better grazing utilization on commercial and research farms, where nutrient composition falls within the range assessed in the current study.

Key words: grass, digestibility, energy, prediction, maintenance feeding

\section{INTRODUCTION}

Livestock production relying on pasture has traditionally been the common practice in certain areas of the world such as parts of the UK, Ireland, and New Zealand (Waghorn and Clark, 2004; Hopkins and Wilkins, 2006; Ferris, 2007). Permanent and temperate grasslands have been increased by 45 and $40 \%$, respectively, between 1900 and 2000 in the UK (Hopkins and Wilkins, 2006), whereas nowadays they account for $95 \%$ of total UK agricultural land (Ferris, 2007). Perennial ryegrass shows a multifunctional importance by (1) reducing production costs when grazed in situ, compared with feeding conserved forage and concentrates indoors, in cool and moist areas suitable for long grazing seasons; (2) being appropriate to be offered as grazing sward, fresh cut, or preserved forage; and (3) sustaining rural landscape and wildlife habitats (Ferris, 
2007). Fresh grass may supply more than half of the energy and protein requirements in ruminants, thus sustaining a moderate level of production, and some production systems totally rely on grassland (Waghorn and Clark, 2004; Hopkins and Wilkins, 2006; Ferris, 2007).

Advances in the fast-moving dairy industry, related to improvements on animal productivity and health, reduction of environmental footprint as well as dairy management and social changes, require in-depth and accurate knowledge of feed nutritive value to maintain economic sustainability of dairy farms. For example, improvement of cow productivity over the last $25 \mathrm{yr}$, as a result of genetic selection over higher milk yields, increased nutrient requirements, thus making it challenging to meet demands of high-yielding cows in grazing systems (Waghorn and Clark, 2004; Ferris, 2007; Phuong et al., 2013). In addition, reduced digestibility of certain nutrients, such as nitrogen $(\mathrm{N})$, by grazing ruminants raises environmental concerns because of the increased outputs of nitrogenous compounds, such as ammonia, nitrous oxide, nitric oxide, di-N, and nitrate (Dijkstra et al., 2013). Productivity and environmental issues therefore necessitate the development of optimum feeding efficiency practices in pasture-based systems; in this effort, predicting as precisely as possible nutrient digestibility and energy concentrations of fresh grass is of eminent importance.

Digestibility of silage-based diets has been extensively investigated, and meta-analyses of existing data have in detail reported factors affecting digestibility of mixed-ration silage-based diets (Huhtanen et al., 2009; Nousiainen et al., 2009). Other authors have published prediction equations for nutrient digestibility in silages, using chemical-composition and fermentation parameters as predictors (Nousiainen et al., 2003; Yan and Agnew, 2004). However, work is limited on the prediction of fresh-grass nutrient digestibility and energy concentrations (Morgan and Stakelum, 1987; Givens et al., 1989, 1990a,b), and the equations used for mixed-ration silage-based diets may not be suitable for grazing animals. Dietary ME is a fundamental unit to assess feeding value of forages and is used to ration dairy cattle (Waghorn and Clark, 2004; Yan and Agnew, 2004). However, experiments assessing nutrient digestibility (in metabolism units) and energy outputs (in calorimetric chambers) are laborious and expensive and consequently impractical for estimating ME of fresh grass at the commercial level (Yan and Agnew, 2004). Development of prediction equations for ME and nutrient digestibility by using routinely and less-costly obtained data at farm level, such as grass chemical composition, would be a valuable tool in developing sustainable grazing and feeding strategies.
The recent renewed interest in pasture-based systems and the limited availability of equations more suitable to grazing cattle, coupled with changes in animal requirements and grass quality over the last decades (Hopkins and Wilkins, 2006; Ferris, 2007), necessitates the development of more up-to-date relations for nutrient digestibility and ME content. The aim of the present study was therefore to (1) investigate relationships between both nutrient digestibility and energy concentrations and grass chemical-composition parameters in nonpregnant, nonlactating cows fed fresh grass at maintenance energy level, and (2) develop prediction equations for nutrient digestibility and energy concentrations, using grass chemical-composition variables as predictors.

\section{MATERIALS AND METHODS}

The present study was performed under the regulations of the Department of Health, Social Services, and Public Safety of Northern Ireland, in line with the Animal (Scientific Procedures) Act 1986 (Home Office, 1986).

\section{Experimental Design}

The present study shows results $(\mathrm{n}=464)$ of a series of digestibility measurements performed over 50 wk, distributed in 3 consecutive grazing seasons (2007, $2008,2009)$ and included 33 nonpregnant, nonlactating dairy cows fed solely fresh-cut grass at maintenance energy level. All experiments were carried out in the ruminant digestibility facilities of Agri-Food and Biosciences Institute, Hillsborough, UK, which are designed for accurate recording of feed intake and feces and urine outputs. Trials were designed to investigate relationships of nutrient composition and digestibility, using a wide range of fresh-cut-grass quality from a range of perennial ryegrass swards of contrasting management practices known to strongly affect chemical composition, such as harvest date, fertilizer input, and maturity stage.

Swards were initially trimmed throughout at a residual height of $4 \mathrm{~cm}$ at (1) early and mid April of $2008(\mathrm{n}=2)$ and $2009(\mathrm{n}=2)$ for the primary-growth swards, (2) late May of $2007(\mathrm{n}=1)$ and early June $2008(\mathrm{n}=2)$ for the first-regrowth swards, and (3) mid August of $2007(\mathrm{n}=1)$ and early and mid August 2008 ( $\mathrm{n}=2$ ) for the second-regrowth swards. All swards were then allowed to grow for 2 to $3 \mathrm{wk}$ (at an average height of $15 \mathrm{~cm}$ ) before being harvested daily at 1300 $\mathrm{h}$ for a 7 -wk period for each sward from early growth to late maturity and offered to cows at a maintenance energy level. 
Grass was cut using a Haldrup 1500 Plot Combine (Haldrup, UK), which immediately transfers forage into the container through a conveyor belt. Fresh herbage was offered twice daily at equal meals with one portion given at $1400 \mathrm{~h}$ and the other at $0900 \mathrm{~h}$ the following day. The second portion was stored on an individual-cow basis in a cool and airy place and was regularly monitored to minimize risk of fermentation. Two groups of 4 cows, balanced for age, BW, and BCS, were allocated a sward. These cows were managed under restricted grazing on a sward similar to the experimental sward for $2 \mathrm{wk}$ before commencing their designed measurement periods. The first group of cows was transferred to individual metabolism pens and offered the diet of solely fresh-cut grass at maintenance energy level for 4 wk with separate collection of feces and urine outputs taking place daily between wk 2 and 4. During the fourth week, the same grass was also offered to the second group of 4 cows, and feces and urine outputs were collected for both groups over the last $3 \mathrm{~d}$ in wk 4, thus allowing assessment of the effect of group of cows on the digestibility data, which was found to be nonsignificant (results not shown). Daily measurements with the second group of cows continued until the end of wk 7. As a result, each sward was evaluated with total collection of feces and urine on a daily basis from early to late growth for 6 wk after 3 to 4 wk of the initial trim. Animals had free access to water throughout the adaptation and experimental periods.

In total, 8 perennial ryegrass swards were used in 2007 and 2008, representing primary growth $(\mathrm{n}=2)$, first regrowth $(\mathrm{n}=3)$, and second regrowth $(\mathrm{n}=3)$ over the first 2 yr. In 2009, a short study was carried out with 2 groups of 4 cows offered primary-growth grass in 2 different swards, thus compensating the shortage of records on feces and urine output and composition from cows fed primary-growth grass in 2007. This short study was undertaken using the same design as that for the first group of cows in 2007 and 2008, but the measurements were only taken for $2 \mathrm{wk}$.

Different levels of $\mathrm{N}$ fertilizer were applied to produce greater variation in grass chemical composition. In year 1,8 and $54 \mathrm{~kg}$ of $\mathrm{N} /$ ha were used in a first-regrowthand a second-regrowth-stage sward, respectively. In the second year, 2 primary-growth swards were fertilized with 45 or $70 \mathrm{~kg}$ of N/ha each, 2 swards at firstregrowth stage with 40 or $65 \mathrm{~kg}$ of $\mathrm{N} / \mathrm{ha}$ each, and 2 swards at second-regrowth stage with 35 or $60 \mathrm{~kg}$ of N/ ha each. In year 3, 2 swards were fertilized with $59 \mathrm{~kg}$ of $\mathrm{N} / \mathrm{h}$. Sward characteristics and management have been previously described in detail by Stergiadis et al. (2015).

To estimate the quality of grass and amounts to meet maintenance energy requirements, fresh-grass
DM concentration was estimated by microwaving at full power for 3 to $5 \mathrm{~min}$, and grass ME was predicted by the near-infrared spectroscopy technique (Agnew et al., 2000), using an NIRS 5000/6500 Feed and Forage Analyzer (FOSS, Hillerød, Denmark). Requirements of $\mathrm{ME}$ for maintenance were calculated as $0.65 \mathrm{MJ}$ per $\mathrm{kg}$ of metabolic BW $\left(\mathrm{kg}^{0.75}\right)$, as described by Agnew et al. (2004). Fresh-grass requirements for individual cows were calculated using ME requirements for maintenance divided by grass ME and then DM concentrations. Grass ME concentration was estimated using the average value of samples collected daily over the previous 2 d. When predicted by near-infrared spectroscopy, grass ME contents were subsequently compared with actual ME contents measured in vivo; Lin's concordance correlation coefficient test indicated some agreement between the 2 methods (Lin's concordance correlation coefficient $=0.16$ and $95 \% \mathrm{CI}=0.10-0.23)$. Graphical examination of the data showed that the near-infrared spectroscopy method gave lower readings for the majority of cases and especially for in vivo values over 11.0 MJ/kg of DM. Descriptive statistics showed an underprediction of in vivo-measured ME of about $11 \%$, and this resulted in feeding slightly higher maintenance energy requirements $(1.1 \times$ maintenance $)$.

\section{Measurements}

Data-collection protocols were the same among all experiments. Assessments of BW and condition scores were carried out before morning feeding at (1) first day in stalls, (2) a day before the commencement of treatment (feeding the experimental diet), and (3) immediately after the end of the sample-collection period. Assessment of BCS was performed on a scale of 0 (thin) to 5 (very fat) as described by Mulvany (1977). Freshcut grass was thoroughly mixed and was sampled daily, at the same time that it was offered to the cows, from 5 places ( 1 in the center and 4 around the center) of the mass. These 5 subsamples were mixed completely and regrouped into 3 subsamples for (1) near-infrared spectroscopy scanning using an NIRS 5000/6500 Feed and Forage Analyzer (FOSS), (2) oven DM at $85^{\circ} \mathrm{C}$, and (3) oven $\mathrm{DM}$ at $60^{\circ} \mathrm{C}$ for subsequent $\mathrm{N}$, gross energy $(\mathbf{G E})$, water-soluble carbohydrates (WSC), ether extract (EE), NDF, ADF, and ash determination. Total feed intake and refusals were recorded daily. Feces outputs, collected daily, were analyzed for $\mathrm{N}$ content using a Kjeldahl Auto 1030 Analyzer (Tecator, Hoganas, Sweden) in fresh sample. A subsample of fresh feces was incubated for $48 \mathrm{~h}$ in $100^{\circ} \mathrm{C}$ to determine $\mathrm{DM}$; the dried sample was then milled through a $1-\mathrm{mm}$ screen and analyzed for GE, NDF, ADF, and ash contents. Urine outputs, collected daily, were analyzed for $\mathrm{N}$ and GE 
contents. The latter analysis was carried out using a 10 -mL freeze-dried sample in a self-sealing polyethylene bag of known weight and energy concentration. Chemical analyses of feeds, feces, and urine samples were carried out as described in detail by Mayne and Gordon (1984).

The digestible energy (DE) concentration; digestibilities of DM, N, GE, NDF, ADF, and OM; and digestible OM in DM (DOMD) were measured in nonpregnant, nonlactating dairy cows fed at maintenance energy level in metabolism units. The ME concentration was estimated using measured DE intake, measured urine energy output, and predicted methane energy output. The latter was calculated from the equation of Yan and Mayne (2008), which was developed using methaneemission data measured for all experimental cows in the first year of the present study, when cows were regularly housed in respiration calorimetric chambers.

\section{Statistical Analysis}

Analyses of data were performed in GenStat (VSN International, 2013). The residual diagnostics were assessed using normality plots and were found to be acceptable. Prediction equations were derived using data from all 3 experiments performed in consecutive grazing seasons $(2007,2008$, and 2009). The data used $(\mathrm{n}=464)$ represent results averaged to 3 -d recordings. Regression equations were developed using REML (Robinson, 1987; Searle et al., 1992) so that the potential random effects of cow, field, year, harvest date, fertilizer input, maturity stage, and grass variety could be accounted for. Linear regression relationships, where the responses were (1) digestibilities of N, GE, NDF, $\mathrm{ADF}, \mathrm{DM}, \mathrm{OM}$, and DOMD; (2) concentrations of DE and $\mathrm{ME}$; and (3) ratios of $\mathrm{ME} / \mathrm{DE}$ and $\mathrm{ME} / \mathrm{GE}$, and the fixed terms were grass contents of N, GE, WSC, $\mathrm{EE}, \mathrm{NDF}, \mathrm{ADF}$, and ash, were developed either individually or in multiple linear models. The optimum random model for each response was identified by fitting the same fixed effect model and the candidate models of the random variation, using the change in deviance and the Akaike and Bayesian information coefficients and deriving an approximate $\mathrm{R}^{2}$, which represents the amount of variability explained. The latter was defined as the squared correlation of the response and the fitted values. The optimum random models identified from the linear regression analysis were used when developing multiple linear regression equations for the responses. The significance of the terms fitted in the multiple linear regressions was assessed using the Wald statistic.
Further single quadratic regression relationships were examined by the same methodology of linear mixed models using the REML procedure (Robinson, 1987; Searle et al., 1992) by using the same dependent and independent variables either linearly, as presented in Equation 1, or quadratically, as presented in Equation 2 , where the squared term showed a significant effect $(P<0.05)$ :

$$
\begin{gathered}
Y=a+b x \\
Y=a+b x^{2}+c x .
\end{gathered}
$$

Stepwise multiple linear regression analysis with backward elimination was carried out to develop prediction equations with the same sets of variables using Equation 3 (for linear regression) and Equation 4 (for quadratic regression), as shown below:

$$
\begin{gathered}
Y=a+b_{1} x_{1}+b_{2} x_{2}+b_{3} x_{3}+\ldots+b_{n} x_{n} \\
Y=a+b_{1} x_{1}+c_{1} x_{1}^{2}+b_{2} x_{2}+c_{2} x_{2}^{2}+b_{3} x_{3}+c_{3} x_{3}^{2} \\
+\ldots+b_{n} x_{n}+c_{n} x_{n}^{2} .
\end{gathered}
$$

An internal evaluation, according to the method described by Yan et al. (2006), was carried out to validate prediction equations, selected among those with the highest $\mathrm{R}^{2}$ for each predicted variable. The main data set $(\mathrm{n}=464)$ was divided into 2 sub-data sets of $\mathrm{n}=$ 309 (two-thirds of total data) and $\mathrm{n}=155$ (one-third of total data). The former data set was used to develop equations using models of the same combination of explanatory variables and random factors to those generated from the whole data set, whereas the latter was used to evaluate the precision of these new equations. This evaluation was undertaken using the mean-square prediction error (MSPE) technique (Equation 5).

$$
\operatorname{MSPE}=1 / n \Sigma(P-A)^{2},
$$

where $P$ and $A$ are the predicted and actual values, respectively, and $n$ is the number of pair of values of $P$ and $A$ compared. Mean prediction error (MPE) was used to describe the prediction accuracy (Equation 6):

$$
\mathrm{MPE}=\sqrt{\mathrm{MSPE}} /(\Sigma A / n) .
$$

The same one-third of the current data set was also used to validate equations of Givens et al. (1990a,b) for prediction of OM digestibility, DOMD, and ME concentrations, using grass chemical-composition parameters. 
Table 1. Animal data $(\mathrm{n}=464)$, grass chemical composition $(\mathrm{n}=116)$, and nutrient digestibility and energy concentrations $(\mathrm{n}=464)$ recorded over 3 yr $(\mathrm{n}=464)^{1}$

\begin{tabular}{lcccc}
\hline Parameter assessed & Mean & SD & Min & Max \\
\hline Animal data & & & & \\
BW (kg) & 548 & 61.0 & 421 & 722 \\
BCS (1-5) & 2.6 & 0.33 & 1.5 & 3.5 \\
Grass chemical composition (g/kg of DM) & & & & \\
DM (g/kg fresh) & 176 & 46.9 & 103 & 324 \\
Ash & 80 & 16.9 & 40 & 110 \\
Nitrogen & 22.6 & 6.71 & 10.7 & 38.1 \\
GE (MJ/kg of DM) & 18.3 & 0.38 & 16.9 & 19.1 \\
ADF & 267 & 37.2 & 207 & 362 \\
NDF & 503 & 37.0 & 413 & 601 \\
Water-soluble carbohydrates & 158 & 47.9 & 70 & 272 \\
Ether extract & 30 & 7.4 & 16 & 55 \\
Nutrient digestibility (g/g) & & & & \\
DM & 0.801 & 0.0412 & 0.642 & 0.900 \\
Nitrogen & 0.732 & 0.0881 & 0.395 & 0.891 \\
GE (MJ/MJ) & 0.790 & 0.0433 & 0.650 & 0.900 \\
ADF & 0.797 & 0.0466 & 0.643 & 0.898 \\
NDF & 0.803 & 0.0478 & 0.623 & 0.899 \\
OM & 0.828 & 0.0395 & 0.698 & 0.910 \\
Digestible OM in DM & 0.762 & 0.0348 & 0.636 & 0.851 \\
Energy concentrations (MJ/kg of DM) & & & & \\
DE & 14.5 & 0.92 & 11.8 & 16.7 \\
ME & 12.0 & 0.74 & 9.0 & 14.1 \\
ME/DE & 0.827 & 0.0319 & 0.708 & 0.908 \\
ME/GE & 0.653 & 0.0402 & 0.476 & 0.771 \\
\hline
\end{tabular}

${ }^{1}$ Min $=$ minimum value observed, Max $=$ maximum value observed, $\mathrm{GE}=$ gross energy, $\mathrm{DE}=$ digestible energy.

\section{RESULTS}

\section{Animal Data, Grass Nutrient Contents, and Digestibility and Energy Parameters}

The mean, standard deviation, minimum, and maximum for animal BW and condition score and grass chemical composition, nutrient digestibility, and energy concentrations are shown in Table 1. Body weight had a large variation, with heaviest animal showing more than $70 \%$ higher BW than the lightest animal in the experiment. Grass chemical contents also varied greatly; highest recorded contents of DM, N, WSC, EE, and ash were proportionally between 2.8 and 3.9 higher than lowest recorded values. Highest measured contents of GE, NDF, and ADF were 13, 75, and $46 \%$ higher than lowest measured contents. In line with large variation in grass nutrient composition, digestibility variables and energy concentrations also varied greatly. The highest range for nutrient digestibility was observed for $\mathrm{N}$, whose highest recorded digestibility was more than 2-fold than the lowest. For the rest of nutrients (DM, GE, ADF, NDF, OM, DOMD), maximum recorded digestibility was 30 to $44 \%$ higher than the minimum recorded. The maximum values for $\mathrm{DE}$ and $\mathrm{ME}$ concentrations were proportionately 0.42 and 0.57 greater than the minimum values.

\section{Relationships Between Grass Nutrient Contents and Digestibility and Energy Parameters}

The correlation coefficients of linear and quadratic (where the effect of the squared term was significant) relationships between chemical composition and nutrient digestibility or energy parameters in fresh grass are presented in Table 2. Examples of linear and quadratic relationships between nutrient contents and digestibility or energy parameters are presented in Figure 1.

Most relationships showed higher correlation coefficients when quadratic, rather than linear, fitting was used in the regression. However, the effect of the squared term was not significant in the relationships between (1) WSC content and all parameters for nutrient digestibilities and energy concentrations; (2) GE content and digestibilities of DM, N, GE, NDF, and $\mathrm{OM}$, concentrations of DOMD and $\mathrm{ME}$, and ratio of $\mathrm{ME} / \mathrm{GE}$; (3) ratio of ME/DE and N, WSC, EE, and $\mathrm{ADF}$ contents; and (4) ratio of ME/GE and GE, WSC, and NDF contents. Digestibilities of DM, N, GE, NDF, $\mathrm{ADF}$, and $\mathrm{OM}$ and concentrations of $\mathrm{DE}$ were positively related to $\mathrm{N}, \mathrm{GE}$, and $\mathrm{EE}$ contents and negatively related to WSC, NDF, and ADF contents. Similar findings were observed for grass DOMD and ME concentrations, except for the relationships with WSC contents, which were positive. Ratio of ME/DE was negatively 
Table 2. Correlation coefficients of linear (Lin) and quadratic (Quad) relationships between nutrient digestibility (with nonpregnant, nonlactating cows at maintenance-energy feeding level) or energy concentration and grass chemical composition ${ }^{1}$

\begin{tabular}{|c|c|c|c|c|c|c|c|c|c|c|c|c|}
\hline $\begin{array}{l}\text { Parameter } \\
\text { assessed }\end{array}$ & \multicolumn{12}{|c|}{ Grass chemical composition } \\
\hline \multicolumn{13}{|c|}{ Nutrient digestibility } \\
\hline $\mathrm{DM}$ & 0.676 & 0.701 & 0.665 & - & -0.638 & - & 0.676 & 0.710 & -0.696 & -0.716 & -0.707 & -0.732 \\
\hline $\mathrm{N}$ & 0.899 & 0.914 & 0.856 & - & -0.848 & - & 0.871 & 0.884 & -0.853 & -0.864 & -0.862 & -0.865 \\
\hline $\mathrm{ADF}$ & 0.721 & 0.754 & 0.723 & 0.724 & -0.719 & - & 0.734 & 0.762 & -0.727 & -0.743 & -0.725 & -0.748 \\
\hline $\mathrm{OM}$ & 0.757 & 0.776 & 0.754 & - & -0.730 & - & 0.754 & 0.786 & -0.780 & -0.796 & -0.792 & -0.809 \\
\hline DOMD & 0.674 & 0.697 & 0.691 & - & 0.633 & - & 0.670 & 0.718 & -0.696 & -0.711 & -0.723 & -0.753 \\
\hline \multicolumn{13}{|c|}{ Energy concentration } \\
\hline $\mathrm{DE}$ & 0.623 & 0.647 & 0.629 & 0.635 & -0.627 & - & 0.629 & 0.655 & -0.647 & -0.655 & -0.660 & -0.677 \\
\hline $\mathrm{ME}$ & 0.770 & 0.779 & 0.811 & - & 0.716 & - & 0.767 & 0.790 & -0.770 & -0.782 & -0.792 & -0.802 \\
\hline $\mathrm{ME} / \mathrm{DE}$ & -0.781 & - & -0.837 & -0.843 & 0.707 & - & -0.742 & - & 0.693 & 0.704 & 0.700 & - \\
\hline
\end{tabular}

${ }^{1} \mathrm{GE}=$ gross energy, WSC $=$ water-soluble carbohydrates, $\mathrm{EE}=$ ether extract, DOMD = digestible OM in DM, DE = digestible energy. Units: $\mathrm{kg} / \mathrm{kg}$ of DM for grass contents of N, WSC, EE, NDF, and ADF; MJ $/ \mathrm{kg}$ of DM for grass GE, DE, and ME; $\mathrm{kg} / \mathrm{kg}$ for digestibilities of DM, N, $\mathrm{NDF}, \mathrm{ADF}$, and $\mathrm{OM}$ and DOMD; MJ/MJ for digestibility of GE and ME/DE and ME/GE ratios. A combination of potential random effects of cow, field, year, harvest date, fertilizer input, maturity stage, and grass variety was accounted for accordingly for each predicted variable. Empty cells represent nonsignificant effect of the squared term in the relation.

associated with N, GE, and EE contents and positively associated with WSC, NDF, and ADF contents. Ratio of ME/GE was negatively related with $\mathrm{N}, \mathrm{GE}, \mathrm{NDF}$, and $\mathrm{ADF}$ contents and positively related with WSC and EE contents. Relating grass nutrient contents with digestibility and energy parameters showed (1) higher correlation coefficients (ranging from 0.716 to 0.914 ) for digestibilities of N, NDF, and OM and concentrations of ME; (2) relatively lower correlation coefficients (ranging from 0.612 to 0.753 ) for digestibility of $\mathrm{DM}$, DOMD, concentrations of $\mathrm{DE}$, and ratio of $\mathrm{ME} / \mathrm{GE}$; and (3) intermediate correlation coefficients (ranging from 0.693 to 0.843 ) for digestibilities of $\mathrm{ADF}$ and GE and ratio of $\mathrm{ME} / \mathrm{DE}$.

\section{Multiple Prediction Equations for Nutrient Digestibility}

The regression equations of nutrient-digestibility parameters are presented in Table 3. All equations and the effect of each individual predictor shown were significant $(P<0.05)$.

Nitrogen Digestibility. Prediction of N digestibility (Table 3, equations $1 \mathrm{a}-1 \mathrm{e}$ ) showed the highest regression coefficients in the present study (0.77-0.84). Quadratic fitting using grass $\mathrm{N}$ and EE contents improved $\mathrm{R}^{2}$, and N, WSC, ash, and EE or NDF were the significant explanatory variables in linear regressions.

GE Digestibility. Prediction of GE digestibility (Table 3, equations 2a-2c) showed relatively lower $\mathrm{R}^{2}$ (0.54-0.61), and the highest accountable variance was found by using linear regression against grass EE, NDF, $\mathrm{ADF}$, and ash contents. Replacing EE, NDF, and ADF with $\mathrm{N}$ in the equation markedly reduced $\mathrm{R}^{2}$. When a quadratic relationship was used, $\mathrm{N}$ and NDF were identified as significant predictors.

Fiber Digestibility. Relatively high $\mathrm{R}^{2}(0.62-0.68)$ were observed for the prediction of NDF digestibility (Table 3, equations 3a-3i) from grass chemical composition, and quadratic relationships showed superior fitting compared with linear regressions. The best possible fitting was observed for the combination of grass $\mathrm{EE}, \mathrm{NDF}$, and WSC contents, whereas the addition of $\mathrm{N}$ as predictor did not further improve $\mathrm{R}^{2}$. When a range of other 2- or 3-way combinations of the same variables (e.g., N-WSC-EE or N-WSC-NDF or EENDF or N-NDF or N-WSC) were used to predict NDF digestibility, only a marginal decrease in the coefficient of the regression was observed. Linear regression also introduced $\mathrm{ADF}$ or ash as significant predictors for NDF digestibility, but the highest $\mathrm{R}^{2}$ for linear prediction was still similar to the lowest $\mathrm{R}^{2}$ for quadratic prediction.

Lower $\mathrm{R}^{2}$ (0.54-0.62) have been observed for the prediction of ADF, than NDF, digestibility (Table 3, equations $4 \mathrm{a}-4 \mathrm{~h}$ ) from grass chemical composition, and quadratic relationships showed superior fitting compared with linear regressions. The best possible fitting was observed for the combination of grass $\mathrm{N}$, WSC, EE, and NDF contents as predictors, whereas similarly to NDF digestibility prediction, a range of other 2- or 3-way combinations of the same variables 

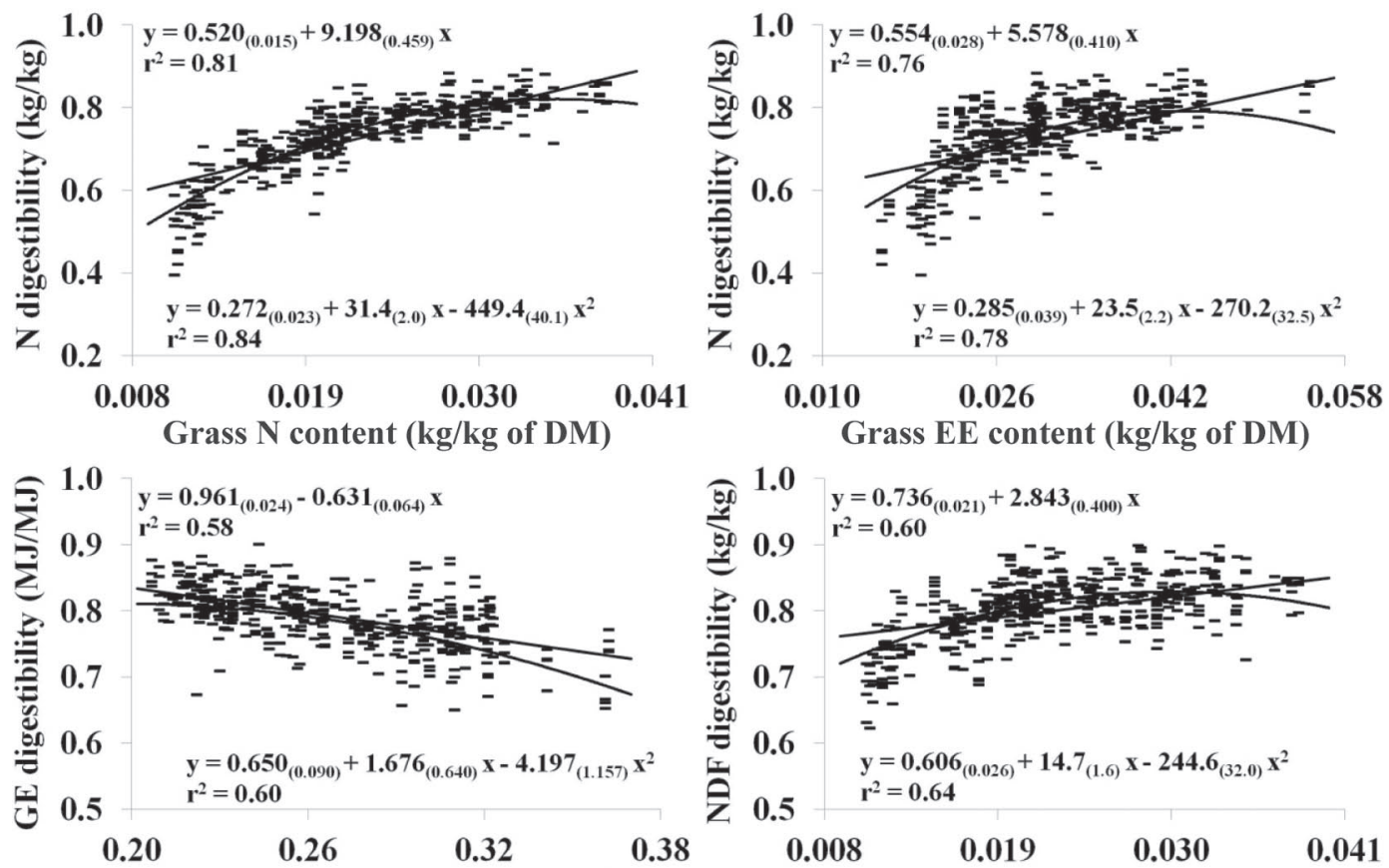

Grass ADF content (kg/kg of DM)

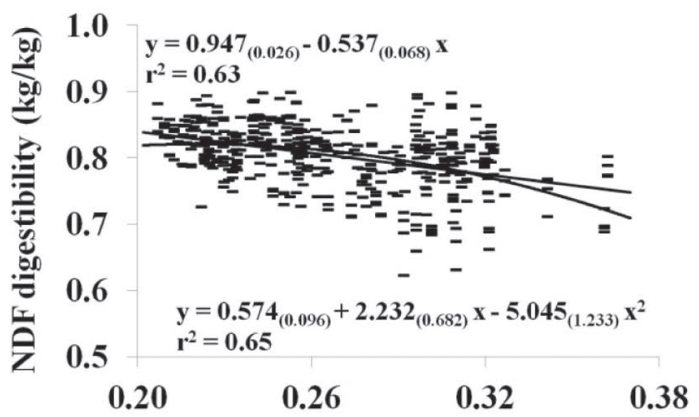

Grass ADF content (kg/kg of DM)
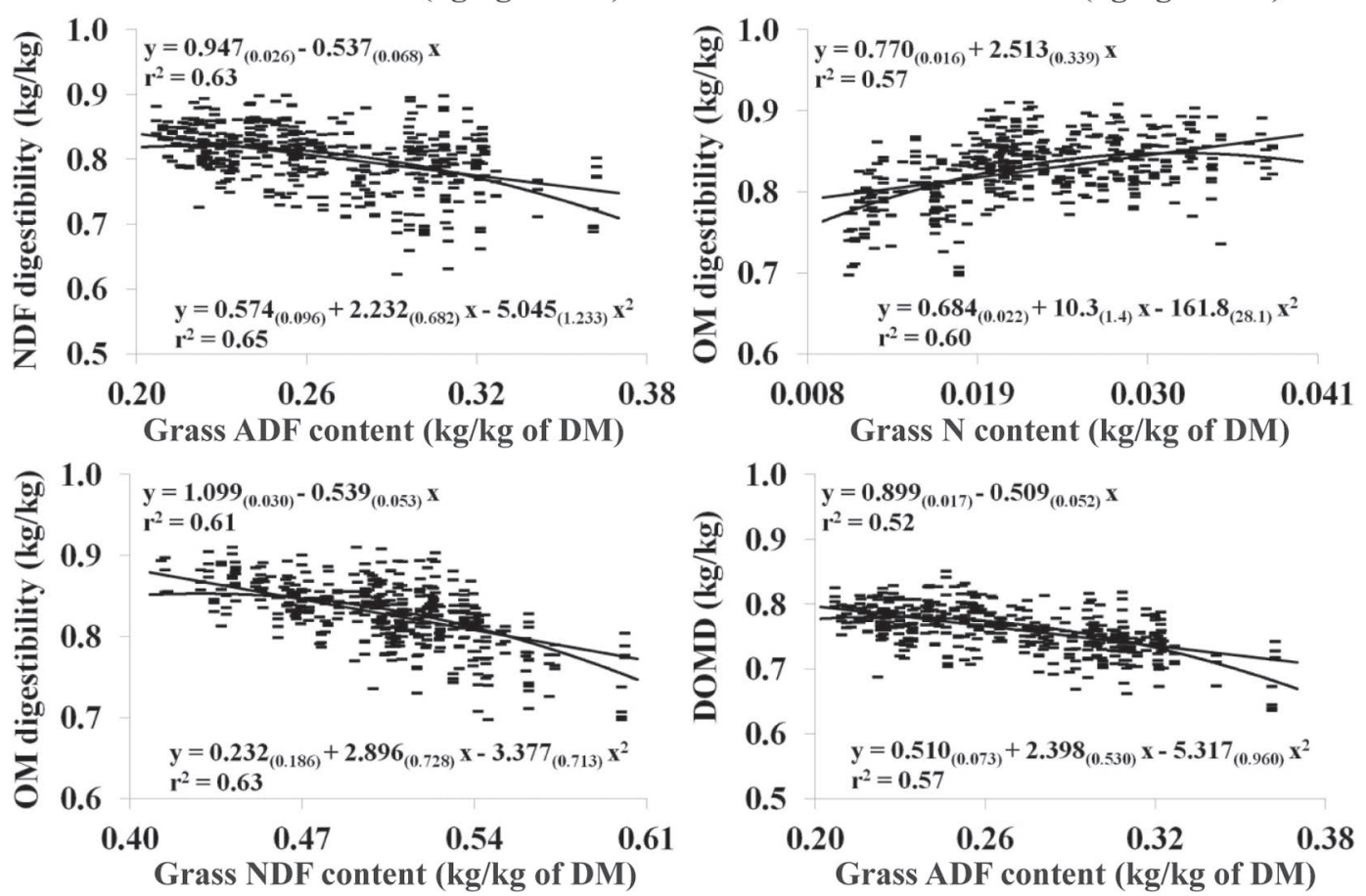

Figure 1. Relationships between nutrient-digestibility parameters (N, GE = gross energy, NDF, OM, DOMD = digestible OM in DM) and grass chemical composition ( $\mathrm{N}, \mathrm{EE}=$ ether extract, $\mathrm{ADF}, \mathrm{NDF}$ ) in fresh grass fed to nonpregnant, nonlactating cows at maintenance-energy feeding level $(\mathrm{n}=464)$. In the presented equations, subscript values in parentheses are SE, and $\mathrm{r}^{2}$ represents the pseudo correlation coefficient.

(e.g., EE-NDF or N-WSC-NDF or N-EE or N-NDF or N-WSC) can be used to predict ADF digestibility with only marginal decrease in the coefficient of the regression. Linear regression also introduced ash content as a significant predictor for ADF digestibility, but the highest $\mathrm{R}^{2}$ for linear relation was still markedly lower than the lowest $\mathrm{R}^{2}$ for quadratic relation.

DM Digestibility. In comparison to other response variables, DM digestibility prediction (Table 3, equations $5 \mathrm{a}-5 \mathrm{~d})$ showed lower $\mathrm{R}^{2}$ values $(0.47-0.57)$. The 
Table 3. Linear and quadratic prediction of nutrient digestibility in fresh grass (with nonpregnant, nonlactating cows at maintenance-energy feeding level) using grass chemicalcomposition parameters ${ }^{1}$

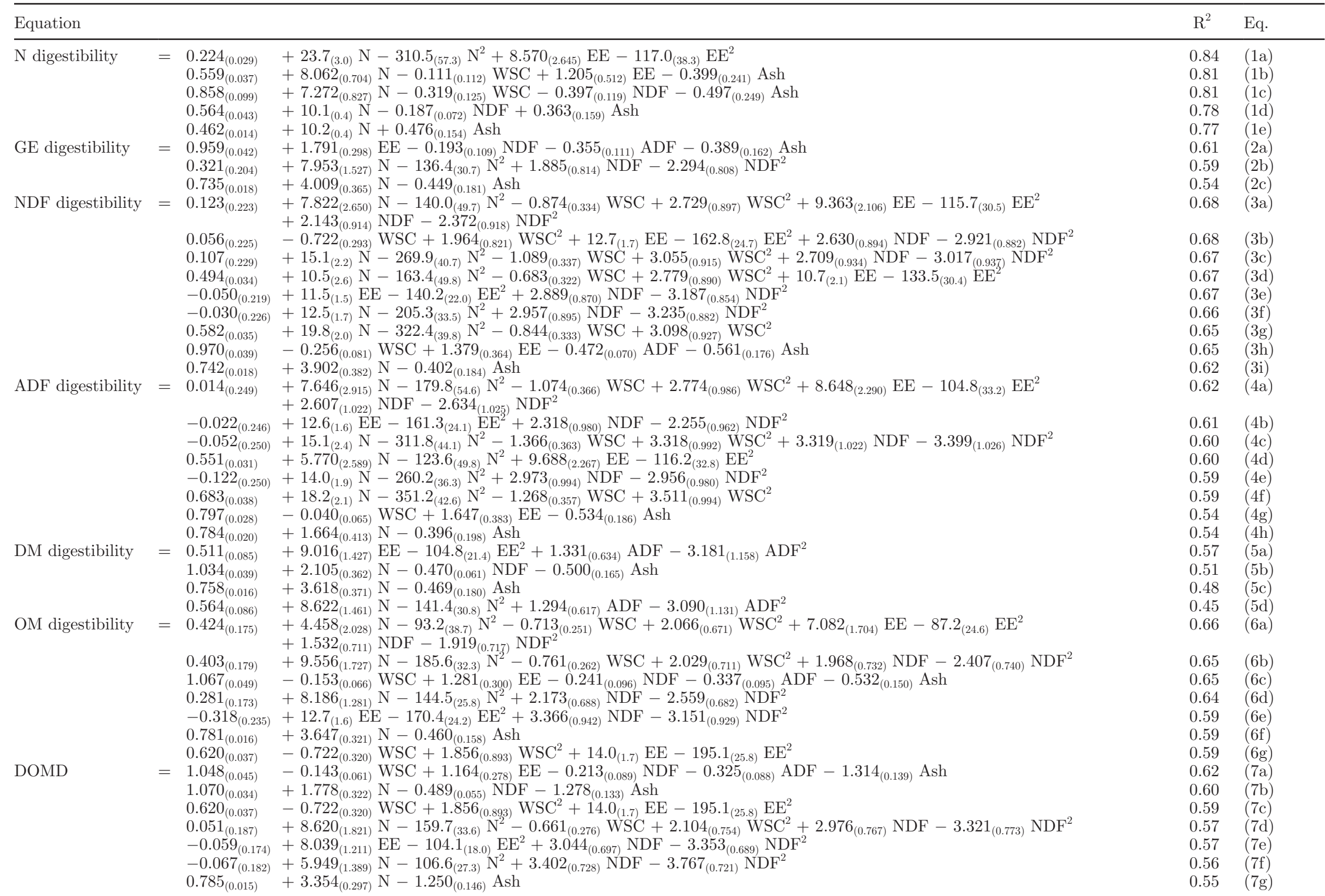

${ }^{1} \mathrm{R}^{2}=$ pseudo correlation coefficient, Eq. = equation, $\mathrm{EE}=$ ether extract, WSC = water-soluble carbohydrates, GE = gross energy, DOMD = digestible OM in DM. Units: kg $\mathrm{kg}$ for digestibilities of $\mathrm{N}, \mathrm{NDF}, \mathrm{ADF}, \mathrm{DM}$, and OM and DOMD; $\mathrm{kg} / \mathrm{kg}$ of DM for grass contents of N, EE, WSC, ash, NDF, and ADF; MJ/MJ for digestibility of GE. Values in subscript parentheses represent SE. A combination of potential random effects of cow, field, year, harvest date, fertilizer input, maturity stage, and grass variety was accounted for accordingly for each predicted variable. 
best fitting in the regression was shown when grass EE and ADF contents were used as explanatory variables into a quadratic relation. When EE was substituted by $\mathrm{N}$, the latter had a significant effect in the quadratic regression but the observed $\mathrm{R}^{2}$ was sharply decreased. Linear regression identified N, NDF, and ash as significant predictors of DM digestibility.

OM Digestibility. Regression equations for OM digestibility against grass chemical composition (Table 3 , equations $6 \mathrm{a}-6 \mathrm{~g})$ showed relatively high correlation coefficients $(0.59-0.66)$. The highest fitting in the regression was observed when grass N, WSC, EE, and NDF contents were used as explanatory variables in a quadratic relation. However, excluding EE from the latter equation or replacing $\mathrm{N}$ with $\mathrm{ADF}$ and ash, using linear regression, would only marginally decrease the explained variation. Using only $\mathrm{N}$ and NDF contents as predictors in a quadratic equation would still slightly decrease $\mathrm{R}^{2}$ compared with the best possible fitting for OM digestibility. Other combinations of explanatory variables were also identified as significant in the regression (e.g., EE-NDF or WSC-EE in quadratic relation or $\mathrm{N}$-ash in linear relation), but these equations showed lower correlation coefficients.

Prediction of DOMD from grass chemical composition (Table 3, equations $7 \mathrm{a}-7 \mathrm{~g}$ ) showed moderate correlation coefficients $(0.55-0.62)$. The highest correlation coefficient was seen when grass WSC, EE, NDF, ADF, and ash contents were used as explanatory variables in a linear regression. However, replacing WSC, EE, and ADF with $\mathrm{N}$ only slightly decreased the correlation coefficient. Using only WSC and EE as predictors in a quadratic equation would further slightly decrease $r^{2}$ compared with the highest possible explained variation of DOMD. Other combinations of explanatory variables were also identified as significant in the regression (e.g., N-WSC-NDF or EE-NDF or N-NDF in quadratic relation or $\mathrm{N}$-ash in linear relation), but these equations showed lower correlation coefficients.

\section{Multiple Prediction Equations for Energy Concentrations and Ratios}

Digestible Energy. Prediction of DE from grass chemical composition (Table 4, equations 8a-8f) showed relatively high $\mathrm{R}^{2}(0.63-0.73)$. The highest $\mathrm{R}^{2}$ was found when a linear regression was developed using grass GE, EE, NDF, ADF, and ash as explanatory variables. Excluding EE, NDF, and ash contents from the latter equation would still produce a high, although decreased, correlation coefficient. Using a combination of $\mathrm{N}$ and $\mathrm{GE}$ in a linear regression or $\mathrm{EE}$ and $\mathrm{NDF}$ in a quadratic regression would reduce the number of predictors but also further decrease $\mathrm{R}^{2}$. Predicting $\mathrm{DE}$ concentrations from $\mathrm{N}$ and $\mathrm{NDF}$ or $\mathrm{ADF}$ using quadratic or linear relations was still possible but showed the lowest $\mathrm{R}^{2}$.

$\boldsymbol{M E}$. Variation explained in equations where $\mathrm{ME}$ concentration was predicted from grass chemicalcomposition parameters (Table 4, equations 9a-9d)

Table 4. Linear and quadratic prediction of energy concentrations and ratios in fresh grass (with nonpregnant, nonlactating cows at maintenanceenergy feeding level) using grass chemical-composition parameters ${ }^{1}$

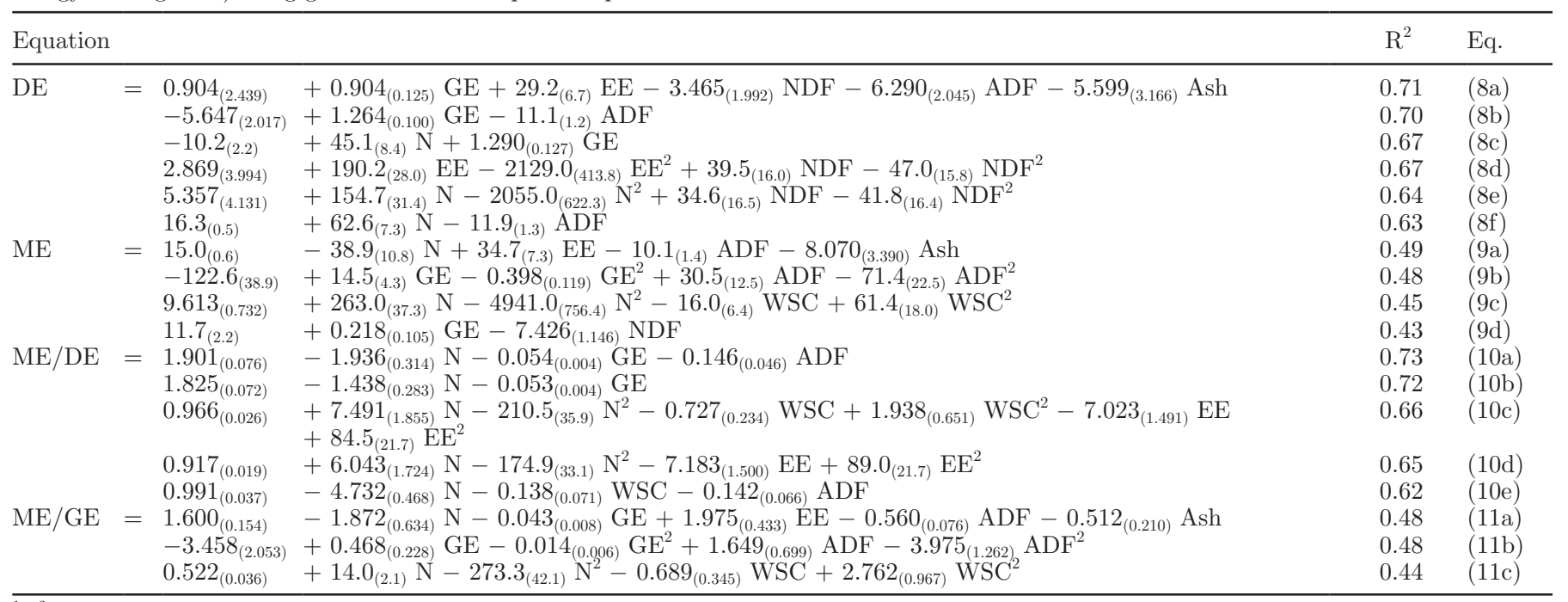

${ }^{1} \mathrm{R}^{2}=$ pseudo correlation coefficient, Eq. = equation, $\mathrm{DE}=$ digestible energy, GE = gross energy, EE = ether extract, WSC $=$ water-soluble carbohydrates. Units: $\mathrm{MJ} / \mathrm{kg}$ of DM for grass DE, ME, and GE; $\mathrm{kg} / \mathrm{kg}$ of DM for grass contents of EE, NDF, ADF, ash, N, and WSC; MJ/ MJ for ME/DE and ME/GE ratios. Values in subscript parentheses represent SE. A combination of potential random effects of cow, field, year, harvest date, fertilizer input, maturity stage, and grass variety was accounted for accordingly for each predicted variable. 
was relatively low ( $\mathrm{R}^{2}$ between 0.43 and 0.49 ). The highest $\mathrm{R}^{2}$ was found when grass $\mathrm{N}, \mathrm{EE}, \mathrm{ADF}$, and ash contents were used as explanatory variables in a linear regression, whereas substituting $\mathrm{N}, \mathrm{EE}$, and ash with GE, and using a quadratic relation, would only marginally reduce regression coefficient. Other quadratic or linear relations identified N and WSC or GE and NDF as significant predictors, respectively, but the $\mathrm{R}^{2}$ of the regression was further decreased.

Energy Ratios. Prediction of ME/DE ratio from grass chemical composition (Table 4, equations 10a10e) showed relatively high correlation coefficients (0.62-0.72). The best fitting was seen when a linear relationship between ME/DE ratio and grass contents of $\mathrm{N}$ and GE was developed. Substituting GE with ADF and WSC would markedly decrease the accountable variance. Using quadratic regression would decrease $\mathrm{R}^{2}$, although using N, WSC, and EE contents as predictors would still predict ME/DE ratio satisfactorily. Further excluding WSC contents from the predictors of the latter equation would only marginally decrease $\mathrm{R}^{2}$.

Variation explained in equations where $\mathrm{ME} / \mathrm{GE}$ was predicted from grass chemical-composition parameters (Table 4, equations 11a-11c) was relatively low $\left(\mathrm{R}^{2}\right.$ between 0.44 and 0.48 ). The best fitting was observed by using either (1) grass N, GE, EE, ADF, and ash contents in a linear regression or (2) grass GE and ADF contents in a quadratic regression. Quadratic regression identified that N and WSC were significant explanatory variables for the prediction of $\mathrm{ME} / \mathrm{GE}$ ratio, but they explained less variation.

\section{Internal Validation of Prediction Equations}

Two new prediction equations for each nutrientdigestibility or energy-concentration variable were developed using the two-thirds of data and are presented in Table 5 (equations $\mathrm{i}$ to xxii). These new equations were evaluated using the remaining one-third of data, and the outcome of the validation process is presented in Table 6. Mean predicted values were very close to the actual data for all predicted nutrient-digestibility and energy-concentrations parameters and represented from 99.2 to $100.6 \%$ the actual value for all variables except for $\mathrm{ME} / \mathrm{GE}$ prediction that showed a range between 102.3 and $128.0 \%$. Mean difference between predicted and actual value represented less than $0.6 \%$ of the actual value for most of the response variables, ranging from -16.7 to $30.3 \%$, with both extremes observed when $\mathrm{N}$ digestibility was predicted from N, WSC, NDF, and ash (equation ii). Difference between predicted and actual values was slightly higher in the cases of prediction of grass ME concentrations (-1.0 and 1.7\%, ranging from -18.5 to $23.8 \%$ ) and ratio of $\mathrm{ME} / \mathrm{GE}$ $(2.3 \%$, ranging from -16.5 to $25.4 \%)$. A relatively high proportionate difference $(21.3 \%$, ranging from -16.5 to $25.4 \%$ ) between predicted and actual values was only observed for the prediction of $\mathrm{ME} / \mathrm{GE}$ ratio when $\mathrm{N}$, $\mathrm{ADF}$, and ash were removed as predictors from the optimum model that also included GE and ADF (equation xxii). Mean prediction errors were (1) lower for the prediction of OM digestibility, DOMD, and ME/ DE ratio (0.044-0.053); (2) higher for the prediction of $\mathrm{N}$ digestibility, $\mathrm{ME}$ concentrations, and ratio $\mathrm{ME} /$ GE (0.086-0.098 but with MPE for equation xxii being 0.238); and (3) showed intermediate values for the predictions of NDF, GE, DM, and ADF digestibilities and DE concentrations (0.061-0.071). Standard errors for the predictions of nutrient-digestibility parameters ranged from 1.8 to $5.3 \%$ of the actual value, whereas the corresponding proportions for the prediction of energy parameters were between 2.2 and $4.4 \%$. Equations previously published for the prediction of $\mathrm{OM}$ digestibility, DOMD, and ME concentrations (Givens et al., 1990a,b) from grass chemical composition were also validated against the same one-third of data set, and results are presented in Table 7 . Their prediction accuracy will be discussed in the relevant parts in the Discussion section.

\section{DISCUSSION}

In comparison with other works that developed prediction equations for nutrient digestibility and energy concentrations of fresh grass, the present study showed some exclusive characteristics. First, the usefulness of the developed prediction equations for fresh-grass nutrient digestibility and energy concentrations can be reassured by (1) the wide range of grass quality used, as a result of feeding grass of 3 harvest dates, 9 fertilization rates, and of maturity stages between 3 and 9 wk, and (2) the relatively high number of records $(\mathrm{n}=$ 464 , as a result of 1,392 three-day averaged records) for digestibility studies with fresh-grass diets being more than 2.5 times higher than previously reported $(\mathrm{n}=$ 173, Givens et al., 1989, 1990a,b; $\mathrm{n}=35$, Morgan and Stakelum, 1987). Second, this is the first study that developed nutrient-digestibility and energy-concentration prediction equations using nonpregnant, nonlactating dairy cows fed at maintenance energy level; previous work for developing similar equations for grass has been carried out with sheep offered previously frozen grass (Givens et al., 1989, 1990a,b). Third, prediction models in the present study provided a broad selection of equations, using basic grass nutrient contents (N, WSC, EE, $\mathrm{NDF}, \mathrm{ADF}$, and ash) and combinations of predictors 
Table 5. Internal validation: linear and quadratic prediction of nutrient digestibility (with nonpregnant, nonlactating cows at maintenance-energy feeding level), energy concentrations, and ratios in fresh grass, using grass chemical-composition parameters and two-thirds of the whole data set $(\mathrm{n}=309)^{1}$

\begin{tabular}{|c|c|c|c|c|}
\hline Equation & & & $\mathrm{R}^{2}$ & Eq. \\
\hline N digestibility & $=0.215_{(0.030)}$ & $+26.2_{(3.3)} \mathrm{N}-349.8_{(64.6)} \mathrm{N}^{2}+6.952_{(2.888)} \mathrm{EE}-96.0_{(41.5)} \mathrm{EE}^{2}$ & 0.86 & i \\
\hline & $0.788_{(0.115)}$ & $+7.784_{(0.956)} \mathrm{N}-0.235_{(0.145)} \mathrm{WSC}-0.362_{(0.138)} \mathrm{NDF}-0.174_{(0.291)}$ Ash & 0.83 & ii \\
\hline GE digestibility & $=0.929_{(0.048)}$ & $+1.490_{(0.344)} \mathrm{EE}-0.123_{(0.124)} \mathrm{NDF}-0.444_{(0.125)} \mathrm{ADF}-0.041_{(0.179)} \mathrm{Ash}$ & 0.64 & iii \\
\hline & $0.566_{(0.232)}$ & $+8.132_{(1.687)} \mathrm{N}-136.9_{(34.0)} \mathrm{N}^{2}+0.920_{(0.925)} \mathrm{NDF}-1.364_{(0.922)} \mathrm{NDF}^{2}$ & 0.62 & iv \\
\hline NDF digestibility & $=0.399_{(0.261)}$ & $\begin{array}{l}+10.4_{(3.1)} \mathrm{N}-171.0_{(58.2)} \mathrm{N}^{2}-1.052_{(0.370)} \mathrm{WSC}+3.305_{(1.003)} \mathrm{WSC}^{2}+8.267_{(2.429)} \mathrm{EE}-105.4_{(34.9)} \mathrm{EE}^{2}+0.928_{(1.088)} \mathrm{NDF} \\
-1.087_{(1.107)} \mathrm{NDF}^{2}\end{array}$ & 0.70 & $\mathrm{v}$ \\
\hline ADF digestibility & $=0.376_{(0.263)}$ & $\begin{array}{l}+17.0_{(2.5)} \mathrm{N}-293.0_{(45.0)} \mathrm{N}^{2}-1.200_{(0.367)} \mathrm{WSC}+3.542_{(1.010)} \mathrm{WSC}^{2}+1.440_{(1.097)} \mathrm{NDF}-1.681_{(1.115)} \mathrm{NDF}^{2} \\
+10.0_{(3.4)} \mathrm{N}-204.0_{(63.6)} \mathrm{N}^{2}-1.348_{(0.412)} \mathrm{WSC}+3.737_{(1.109)} \mathrm{WSC}^{2}+8.532_{(2.627)} \mathrm{EE}-109.5_{(37.7)} \mathrm{EE}^{2}+0.784_{(1.207)} \mathrm{NDF} \\
-0.798_{(1.224)} \mathrm{NDF}^{2}\end{array}$ & $\begin{array}{l}0.70 \\
0.63\end{array}$ & $\begin{array}{l}\text { vi } \\
\text { vii }\end{array}$ \\
\hline DM digestibility & $\begin{aligned} & 0.365_{(0.290)} \\
& 0.673_{(0.093)} \\
& 1.030^{0.044}\end{aligned}$ & $\begin{array}{l}+17.4_{(2.7)} \mathrm{N}-340.2_{(49.0)} \mathrm{N}^{2}-1.527_{(0.400)} \mathrm{WSC}+4.050_{(1.099)} \mathrm{WSC}^{2}+1.508_{(1.206)} \mathrm{NDF}-1.577_{(1.223)} \mathrm{NDF}^{2} \\
+9.809_{(1.472)} \mathrm{EE}-117.5_{(22.1)} \mathrm{EE}^{2}+0.085_{(0.694)} \mathrm{ADF}-0.997_{(1.274)} \mathrm{ADF}^{2} \\
+2.215_{(0.20)} \mathrm{N}-0.494^{(0.9)} \mathrm{NDF}-0.356_{(0.10)} \mathrm{Ash}\end{array}$ & $\begin{array}{l}0.62 \\
0.60 \\
0.56\end{array}$ & $\begin{array}{l}\text { viii } \\
\text { ix } \\
x\end{array}$ \\
\hline OM digestibility & $=0.671_{(0.202)}$ & $\begin{array}{l}+2.215_{(0.398)} \mathrm{N}-0.494_{(0.069)} \mathrm{NDF}-0.356_{(0.190)} \mathrm{Ash} \\
+4.799_{(2.346)} \mathrm{N}-91.1_{(44.5)} \mathrm{N}^{2}-0.702_{(0.281)} \mathrm{WSC}+2.114_{(0.752)} \mathrm{WSC}^{2}+6.521_{(1.905)} \mathrm{EE}-83.4_{(27.1)} \mathrm{EE}^{2}+0.547_{(0.831)} \mathrm{NDF} \\
-0.942_{(0.843)} \mathrm{NDF}^{2}\end{array}$ & $\begin{array}{l}0.56 \\
0.69\end{array}$ & $\begin{array}{l}\mathrm{x} \\
\mathrm{xi}\end{array}$ \\
\hline & $0.637_{(0.205)}$ & $+9.985_{(1.897)} \mathrm{N}-187.9_{(35.1)} \mathrm{N}^{2}-0.747_{(0.286)} \mathrm{WSC}+2.110_{(0.777)} \mathrm{WSC}^{2}+0.973_{(0.847)} \mathrm{NDF}-1.414_{(0.861)} \mathrm{NDF}^{2}$ & 0.68 & xii \\
\hline DOMD & $\begin{aligned}= & 1.029_{(0.053)} \\
& 1.009_{(0.034)}\end{aligned}$ & $\begin{array}{l}-0.157_{(0.067)} \mathrm{WSC}+0.794_{(0.326)} \mathrm{EE}-0.167_{(0.101)} \mathrm{NDF}-0.388_{(0.099)} \mathrm{ADF}-0.999_{(0.155)} \text { Ash } \\
+1.476_{(0.348)} \mathrm{N}-0.404_{(0.054)} \mathrm{NDF}-0.985_{(0.138)} \mathrm{Ash}\end{array}$ & $\begin{array}{l}0.63 \\
0.60\end{array}$ & $\begin{array}{l}\text { xiii } \\
\text { xiv }\end{array}$ \\
\hline $\mathrm{DE}$ & $\begin{aligned}= & -2.279_{(2.508)} \\
& -4.615_{(2.232)}\end{aligned}$ & $\begin{array}{l}+1.044_{(0.128)} \mathrm{GE}+18.5_{(7.5)} \mathrm{EE}-2.349_{(2.219)} \mathrm{NDF}-7.399_{(2.230)} \mathrm{ADF}+2.765_{(3.373)} \text { Ash } \\
+1.223_{(0.112)} \mathrm{GE}-12.2_{(1.3)} \mathrm{ADF}\end{array}$ & $\begin{array}{l}0.74 \\
0.74\end{array}$ & $\begin{array}{l}\text { xv } \\
\text { xvi }\end{array}$ \\
\hline ME & $\begin{aligned}= & 14.8_{(0.7)} \\
& -144.7_{(41.9)}\end{aligned}$ & $\begin{array}{l}-30.2_{(12.2)} \mathrm{N}+26.2_{(8.5)} \mathrm{EE}-10.5_{(1.5)} \mathrm{ADF}-3.789_{(3.923)} \mathrm{Ash} \\
+17.3_{(4.7)} \mathrm{GE}-0.478_{(0.130)} \mathrm{GE}^{2}+13.0_{(13.6)} \mathrm{ADF}-42.5_{(24.7)} \mathrm{ADF}^{2}\end{array}$ & $\begin{array}{l}0.53 \\
0.54\end{array}$ & $\begin{array}{l}\text { xvii } \\
\text { xvii }\end{array}$ \\
\hline $\mathrm{ME} / \mathrm{DE}$ & $=1.845_{(0.085)}$ & $-1.159_{(0.329)} \mathrm{N}-0.054_{(0.005)} \mathrm{GE}$ & 0.74 & xix \\
\hline $\mathrm{ME} / \mathrm{GE}$ & $\begin{aligned} & 0.958_{(0.030)} \\
= & 1.481_{(0.171)} \\
& -3.833_{(2.199)}\end{aligned}$ & $\begin{array}{l}+9.482_{(2.243)} \mathrm{N}-242.2_{(43.0)} \mathrm{N}^{2}-0.690_{(0.267)} \mathrm{WSC}+1.849_{(0.743)} \mathrm{WSC}^{2}-8.392_{(1.764)} \mathrm{EE}+103.2_{(25.5)} \mathrm{EE}^{2} \\
-1.556_{(0.721)} \mathrm{N}-0.037_{(0.009)} \mathrm{GE}+1.389_{(0.497)} \mathrm{EE}-0.576_{(0.084)} \mathrm{ADF}-0.203_{(0.243)} \mathrm{Ash} \\
+0.530_{(0.245)} \mathrm{GE}-0.016_{(0.007)} \mathrm{GE}^{2}+0.666_{(0.774)} \mathrm{ADF}-2.336_{(1.407)} \mathrm{ADF}^{2}\end{array}$ & $\begin{array}{l}0.69 \\
0.53 \\
0.55\end{array}$ & $\begin{array}{c}\text { xx } \\
\text { xxi } \\
\text { xxii }\end{array}$ \\
\hline
\end{tabular}

尊 ${ }^{1} \mathrm{R}^{2}=$ pseudo correlation coefficient, Eq. = equation, $\mathrm{EE}=$ ether extract, WSC $=$ water-soluble carbohydrates, GE $=$ gross energy, DOMD $=$ digestible OM in DM, DE $=$ digestible energy. Units: $\mathrm{kg} / \mathrm{kg}$ for digestibilities of N, NDF, ADF, DM, and OM and DOMD; $\mathrm{kg} / \mathrm{kg}$ of DM for grass contents of N, EE, WSC, NDF, ash, and ADF; MJ/MJ for digestibility

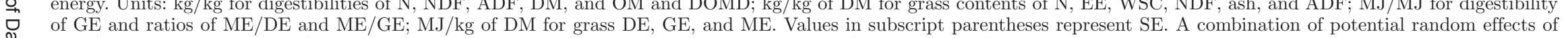
ow, field, year, harvest date, fertilizer input, maturity stage, and grass variety was accounted for accordingly for each predicted variable. 
Table 6. Internal validation using one-third of the whole data set $(\mathrm{n}=155)$ and equations ${ }^{1}$ developed from the remaining two-thirds of the whole data set $(\mathrm{n}=309)^{2}$

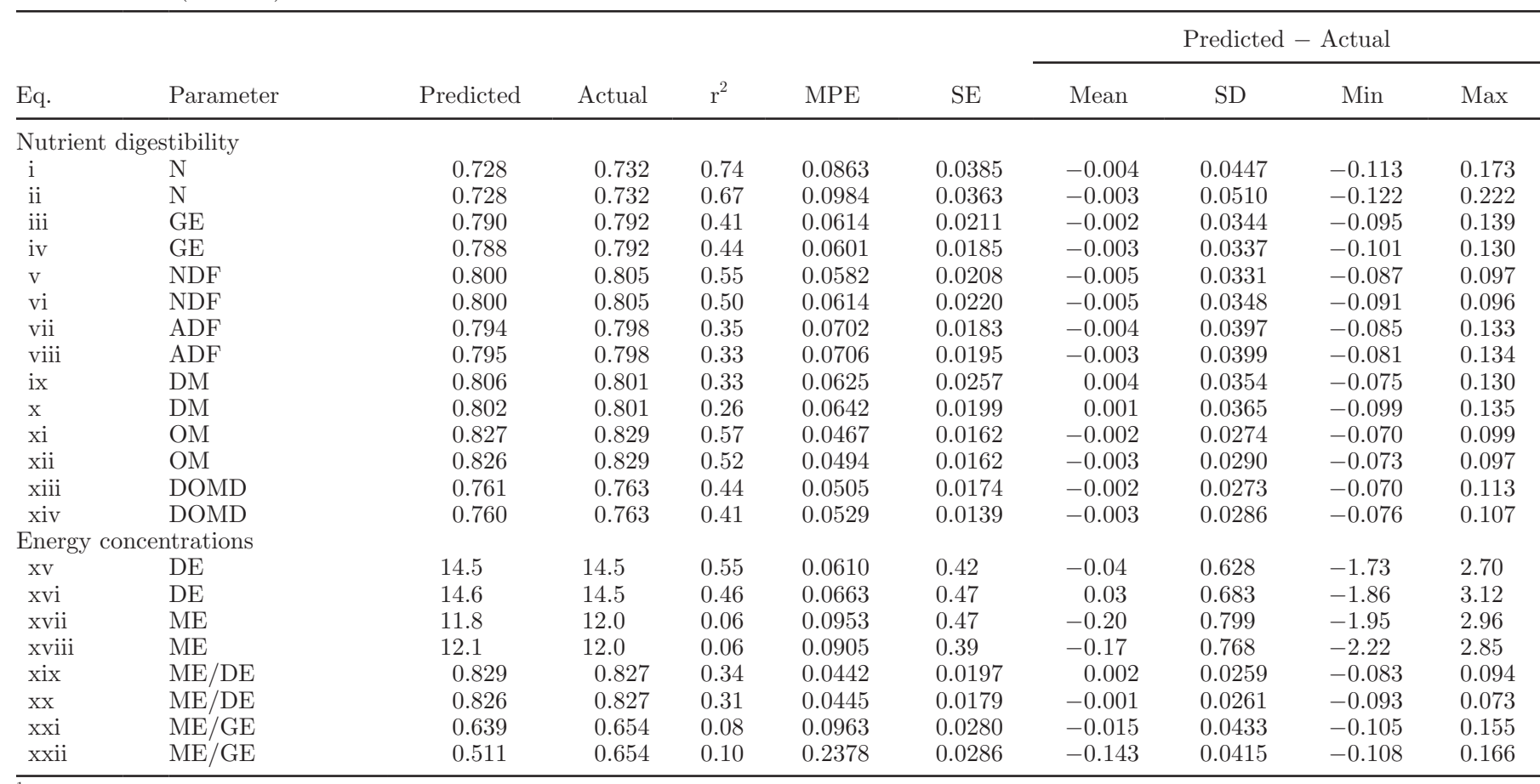

${ }^{1}$ All equations are presented in Table 5 .

${ }^{2}$ Eq. $=$ equation, $\mathrm{r}^{2}=$ correlation between predicted and actual values, MPE $=$ mean prediction error, Min $=$ minimum value observed, Max $=$ maximum value observed, $\mathrm{GE}=$ gross energy, $\mathrm{DOMD}=$ digestible $\mathrm{OM}$ in $\mathrm{DM}, \mathrm{DE}=$ digestible energy. Units: $\mathrm{kg} / \mathrm{kg}$ for digestibilities of $\mathrm{N}$, $\mathrm{NDF}, \mathrm{ADF}, \mathrm{DM}$, and $\mathrm{OM}$ and DOMD; MJ/MJ for digestibility of GE and ratios of ME/DE and ME/GE; MJ/kg of DM for grass DE and ME.

that have not been presented before, allowing broad utilization at farm level depending on what analyses are available.

Equations developed in the current study had higher accountable variance and lower MPE and standard er- rors when validated against one-third of the current data set for the majority of the predictions compared with other studies (Givens et al., 1990a,b), possibly partly because of the wider data set and combinations of explanatory variables used.

Table 7. Validation of published prediction equations for digestibility parameters and energy concentrations from laboratory measurements of previously frozen grass offered to wether sheep at maintenance-energy level, using one-third of the whole data set $(n=155)^{1}$

\begin{tabular}{|c|c|c|c|c|c|c|c|c|c|c|}
\hline \multirow[b]{2}{*}{ Parameter } & \multirow[b]{2}{*}{ Predictor } & \multirow[b]{2}{*}{ Predicted } & \multirow[b]{2}{*}{ Actual } & \multirow[b]{2}{*}{$r^{2}$} & \multirow[b]{2}{*}{ MPE } & \multirow[b]{2}{*}{$\mathrm{SE}$} & \multicolumn{4}{|c|}{ Predicted - Actual } \\
\hline & & & & & & & Mean & $\mathrm{SD}$ & Min & Max \\
\hline \multicolumn{11}{|c|}{ Nutrient digestibility $^{2}$} \\
\hline $\mathrm{OM}$ & $\mathrm{ADF}$ & 0.793 & 0.829 & 0.30 & 0.0806 & 0.0399 & -0.036 & 0.0387 & -0.15 & 0.11 \\
\hline $\mathrm{OM}$ & NDF & 0.822 & 0.829 & 0.35 & 0.0573 & 0.0273 & -0.007 & 0.0332 & -0.10 & 0.09 \\
\hline $\mathrm{OM}$ & $\mathrm{CP}$ & 0.769 & 0.829 & 0.20 & 0.1049 & 0.0357 & -0.060 & 0.0420 & -0.15 & 0.11 \\
\hline DOMD & $\mathrm{ADF}$ & 0.732 & 0.763 & 0.27 & 0.0770 & 0.0299 & -0.032 & 0.0347 & -0.12 & 0.09 \\
\hline \multicolumn{11}{|c|}{ Energy concentrations ${ }^{3}$} \\
\hline $\mathrm{ME}$ & $\mathrm{ADF}$ & 11.6 & 12.0 & 0.08 & 0.0939 & 0.4893 & 0.18 & 0.730 & -1.67 & 3.22 \\
\hline $\mathrm{ME}$ & $\mathrm{NDF}$ & 12.2 & 12.0 & 0.15 & 0.1106 & 0.6510 & -0.35 & 0.845 & -2.37 & 3.38 \\
\hline $\mathrm{ME}$ & $\mathrm{CP}$ & 11.2 & 12.0 & 0.11 & 0.1198 & 0.5869 & -0.76 & 0.811 & -2.92 & 3.38 \\
\hline
\end{tabular}

${ }_{\mathrm{r}^{2}}=$ correlation between predicted and actual values, $\mathrm{MPE}=$ mean prediction error, Min $=$ minimum value observed, Max $=$ maximum value observed, DOMD = digestible OM in DM. Units: $\mathrm{kg} / \mathrm{kg}$ of DM for digestibility of OM and DOMD; MJ/kg of DM for grass ME.

${ }^{2}$ Equations published in Givens et al. (1990a).

${ }^{3}$ Equations published in Givens et al. (1990b). 


\section{Effect of Grass Nutrients on Digestibility Parameters}

Results on the relations between several grass nutrient contents (N, NDF, ADF); digestibilities of DM, $\mathrm{OM}, \mathrm{N}$, and NDF; and DOMD were very similar to those presented by other authors for grass silages (Yan and Agnew, 2004; Nousiainen et al., 2009) or frozen grass (Givens et al., 1989, 1990a,b).

Nitrogen. The improvement on diet and $\mathrm{N}$ digestibility by increasing dietary $\mathrm{N}$ content across the range observed in this study is possibly due to the high solubility and degradability of fresh-grass $\mathrm{N}$ in the rumen and the fact that the main $\mathrm{N}$ excretion pathway is through urine rather than feces (Hoekstra et al., 2007). The fact that the relation between grass $\mathrm{N}$ contents and digestibility are better described by a quadratic relationship has been previously reported (Givens et al., 1989). In the present study, increase of $\mathrm{N}$ content improved $\mathrm{N}$ digestibility when total grass $\mathrm{N}$ content was lower than about $35 \mathrm{~g} / \mathrm{kg}$ of DM; over this concentration, any increase in grass $\mathrm{N}$ content decreased $\mathrm{N}$ digestibility.

Digestibility of OM and DOMD have been found positively related to herbage $\mathrm{N}$ contents in other digestibility trials using frozen grass (Givens et al., 1989, 1990a). In the present study, a quadratic fitting explained more of the variation on $\mathrm{OM}$ digestibility when $\mathrm{N}$ content was used as predictor; increase of $\mathrm{N}$ content improved OM digestibility for contents lower than about $33 \mathrm{~g} /$ $\mathrm{kg}$ of DM (equals to $20.6 \% \mathrm{CP}$ in $\mathrm{DM}$ ), but over this concentration, any increase in $\mathrm{N}$ content decreased $\mathrm{OM}$ digestibility. This is very similar to results reported for grass silages from other authors $(31 \mathrm{~g} / \mathrm{kg}$ of DM, equals to $19.8 \%$ CP in DM; Yan and Agnew, 2004) indicating a consistency between fresh and ensiled grass in this feature.

Fiber. Overall grass nutrient digestibility may be decreased by increasing NDF and ADF because part of these nutrients is indigestible in the rumen (Givens et al., 1989; Hopkins and Wilkins, 2006). The negative correlations between $\mathrm{OM}, \mathrm{NDF}$, and ADF digestibilities and DOMD with grass NDF and ADF contents are in line with previous studies, although crude fiber, instead of NDF and ADF, was previously used in some equations (Givens et al., 1989, 1990a). On the other hand, $\mathrm{ADF}$ showed poor correlation to $\mathrm{OM}$ digestibility in another study with cows fed fresh-grass diets (Morgan and Stakelum, 1987). The latter experiment was carried out with lactating cows fed at 2.5 times the maintenance level, although several factors, such as harvest date, year, and regrowth interval, may significantly affect this relationship when data from primarygrowth grass, which represented almost $30 \%$ of the data in the present study, is used in the regression (Morgan and Stakelum, 1987). Also, higher feeding levels tend to increase rumen outflow rates and reduce retention times, thus decreasing nutrient degradability in the rumen (McDonald et al., 2002). In the present study, single linear regressions showed that increasing NDF and ADF contents by $0.10 \mathrm{~kg} / \mathrm{kg}$ of DM in grass would proportionately decrease OM digestibility and DOMD by 0.054 and 0.051 , respectively. These values for fresh grass are lower than previous studies that used frozen grass (0.077 and 0.090; Givens et al., 1990a), but in the present study quadratic relations for these predictions explained more of the variation.

$\boldsymbol{W S C}$. Previous studies have reported a positive relation between WSC and digestibilities of NDF, ADF, and DM in fresh grass in vitro (Miller et al., 2001). In the current study, WSC were negatively correlated with all nutrient-digestibility parameters but positively correlated with DOMD. However, despite the negative relations, regression slopes were considerably low, indicating the effect of WSC contents on feeding value of fresh grass may be limited. The latter has been also reported in other studies and has been explained by seasonal variation in DM digestibility mainly due to grass NDF contents that may have masked the actual effect of WSC (Radojevic et al., 1994). The same finding was presented for grass silages (Nousiainen et al., 2009) and was explained by the negative association between dietary WSC and NDF and ADF digestibilities. However, amounts of WSC would be much lower in silages, because of losses during ensiling, and lactic acid and volatile fatty acid concentrations of ensiled forage may also influence DMI and nutrient metabolism (McDonald et al., 2002).

In the present study, the linear relationship between grass WSC contents and nutrient-digestibility parameters showed the highest slopes for N, NDF, and ADF digestibilities (results not shown). In general, this effect of WSC on digestibility may not be causal but can be explained by the negative correlation between WSC and N contents in grass, which has been reported to be strong for CP contents below $200 \mathrm{~g} / \mathrm{kg}$ of DM (Tas, 2006), a range that represented $90 \%$ of the data in the present study. Thus, any improvement in the digestibility of the diet resulting from the higher WSC contents may well have been overridden by the decrease in digestibility due to lower dietary $\mathrm{N}$ supply.

\section{Effect of Grass Nutrients on Energy Parameters}

Nitrogen and $\boldsymbol{G E}$. The positive relation between grass $\mathrm{N}$ and GE and $\mathrm{ME}$ concentrations is in line with previous work (Givens et al., 1990b). The negative relationship between $\mathrm{ME} / \mathrm{DE}$ and $\mathrm{ME} / \mathrm{GE}$ ratios with 
$\mathrm{N}$ contents, which also defined $\mathrm{N}$ intake in the present study where cows were offered solely fresh-cut grass, can be explained by the proportionately higher increase of $\mathrm{N}$ output in urine rather than feces with increasing N intake (Dijkstra et al., 2013; Stergiadis et al., 2015). This decreased ME at a higher rate than DE or GE and resulted in lower ME/DE and ME/GE ratios. Similarly, although the effect of increasing NDF and ADF in fresh grass reduced both DE and ME concentrations (Givens et al., 1990b), this may have a relatively greater effect on feces energy output, thus decreasing DE at a higher rate than ME. The negative relationship between ME/ DE ratio and grass GE contents is in line with previous work and possibly explained by the positive correlation between grass GE and N contents (results not shown), which is in particular higher at spring-growth grass (Givens et al., 1989, 1990b).

Fiber. Fibrous parameters of feed, especially ADF (but also NDF), (1) reduce energy-use efficiency because they contain limited energy to sustain microbial growth, (2) decrease availability of nutrients in highfiber diets, and (3) tend to accelerate rumen filling and limit feed intake (Phuong et al., 2013). These facts are described in the present study by the negative relationship of NDF and ADF with GE digestibility, and concentrations of DE and ME.

\section{Prediction of Nutrient Digestibility}

Prediction of nutrient digestibility by using different combinations of grass chemical contents as explanatory variables was performed by the stepwise multiple regression with backward elimination technique. Relationships between nutrient contents and digestibility were very similar to those described for single regressions.

Assessing Predictors for OM Digestibility. The combination of grass fiber (NDF, ADF) and ash contents for the prediction of DOMD has been previously recommended (Givens et al., 1990a); in the current study, these variables also appeared among the most important predictors of DOMD in the 2 equations that showed the best fit. However, factors such as grass $\mathrm{N}$, WSC, and EE contents maximized the accountable variance in DOMD, indicating an additional important contribution of other nutrients. This is in line with other studies that reported a strong link of N and WSC with diet digestibility (Givens et al., 1990a; Miller et al., 2001), and a quadratic relation between grass EE contents and $\mathrm{N}$ digestibility has also been found in the present study.

Environmental factors, such as sunlight and temperature, may influence grass digestibility without any changes on fiber and ADF, indicating that these vari- ables alone are not sufficient predictors for OM digestibility or DOMD (Givens et al., 1993). In our relations, ADF was not a significant predictor in most equations for OM digestibility and DOMD, but this may be due to the fact that NDF, which explains a large part of the variation caused by fiber, was identified as significant in the same models. Relations of crude fiber and ADF with OM digestibility may be significant when grass is at the primary-growth stage but less relevant when herbage is at first- or second-regrowth stages (Morgan and Stakelum, 1987; Givens et al., 1993). This is because in the regrowth stages, the positive association between cellulose and lignin weakens (Givens et al., 1993). In the present study, NDF and ADF alone showed relatively good fit when used as sole predictors for OM digestibility and DOMD, respectively, despite $70 \%$ of data being from first- and second-regrowth grass, but the use of additional variables (WSC, EE, and $\mathrm{N}$ or ash) explained the variation further, by increasing $R^{2}$ from 0.63 to 0.66 and 0.58 to 0.62 , respectively.

Including grass $\mathrm{EE}$ content as predictor for GE or OM digestibility explained their variation further in previous work (Givens et al., 1989), and the same was observed in the present study, although the change in $\mathrm{R}^{2}$ was relatively small. During the internal validation procedure in the present study, MPE of GE and OM digestibility predictions were very similar whether EE was used as explanatory variable or not; this may imply that omitting EE (usually unavailable at farm level) when estimating GE and OM digestibility would not considerably influence the accuracy of prediction.

Validating the Predictions of OM Digestibility. Regarding prediction of nutrient-digestibility parameters, in particular OM digestibility and DOMD, inclusion of more explanatory variables explained more variation, thus being in line with Givens et al. (1990a). In detail, predicting OM digestibility from measurements of grass N, WSC, NDF, and EE contents showed the most accurate approach; the exclusion of EE would increase prediction error but only marginally, thus an equation using N, WSC, and NDF may be also recommended when EE is not available in practice. Likewise, the error in the prediction of DOMD was minimized when WSC, EE, NDF, ADF, and ash were used as predictors, but substituting WSC, EE, and ADF with $\mathrm{N}$ (which is most commonly available, as $\mathrm{CP}$, at farm level) would not compromise prediction accuracy because the MPE, standard error, and mean difference between actual and predicted DOMD were very similar in both cases.

When models of Givens et al. (1990a) were validated against the same one-third of the data set used to validate equations developed in the current study, they showed higher MPE, standard errors, and mean 
difference between actual and predicted values. This indicates that the equations for the prediction of $\mathrm{OM}$ digestibility and DOMD of the current study may improve the accuracy of prediction in practice, when measurements for more nutrients, other than NDF, ADF, or CP alone, are also available.

\section{Prediction of Energy Concentrations and Ratios}

Different combinations of grass chemical contents were used as predictors to develop multiple linear or quadratic relations with energy concentrations. Relations between nutrients and energy concentrations were in line with those described for single regressions.

Assessing Predictors for Energy Parameters. The development of prediction equations indicated grass GE content as possibly the most important parameter to measure in practice when assessing DE and ME from nutrient composition. Known GE may replace 3 predictors (N, EE, and ash) when estimating $\mathrm{ME}$ and 2 predictors (WSC and EE) when estimating ME/DE without compromising the explained variation; notably, in the latter case it also improved $\mathrm{R}^{2}$ from 0.66 to 0.72 . Grass GE content was also among the main predictors for both $\mathrm{DE}$ concentration and ratio of $\mathrm{ME} / \mathrm{GE}$. However, for the prediction of ME/DE ratio, $\mathrm{N}$ content proved to be an essential predictor by appearing in all equations with high $\mathrm{R}^{2}$. Higher grass $\mathrm{N}$ contents increase $\mathrm{N}$ intake in pasture-based cows and consequently $\mathrm{N}$ output in urine, which is in turn associated with energy losses for ammonia transformation and removal as urea (Waghorn and Clark, 2004; Hoekstra et al., 2007), especially under the absence of readily rumen available energy from concentrate feeds in the current study. It is therefore expected $\mathrm{N}$ contents will affect $\mathrm{ME}$ concentrations and ME/DE ratio (Givens et al., 1989). Consequently, the combination of $\mathrm{N}$ and GE resulted in the best possible prediction equation for $\mathrm{ME}$ and $\mathrm{ME} /$ $\mathrm{DE}$. The range of ratio of ME/DE in the present study was higher (0.71-0.91) than those reported previously for frozen grass (0.75-0.86; Givens et al., 1989), but the possibly greater variation in grass quality used in the present study may explain this finding.

Grass ADF and NDF contents were negatively related to $\mathrm{DE}$ and $\mathrm{ME}$ in all equations that they were identified as significant explanatory variables. This is in line with previous findings that reported increases in energy output in feces (thus reducing DE) and lower ME with increasing NDF and ADF (Givens et al., 1990b).

Grass EE content has been identified among the main predictors for energy parameters, but equations that do not include EE were also developed in the present study, by partially compromising the explained variation, because it is the least commonly available measurement in practice. Slope for EE was higher than for other explanatory variables (WSC, NDF, ash) when it was previously used in prediction equations of GE contents (Givens et al., 1990b), indicating the greater effect that its change may have on a per-weight basis. Similar findings were seen in the present study for the prediction of $\mathrm{DE}$ and $\mathrm{ME} / \mathrm{GE}$ but not for ME, possibly because of the high effect of grass $\mathrm{N}$ content on energy output in urine (Givens et al., 1989).

Validating the Predictions of Energy Parameters. Based on the internal validation, the best equation to predict DE would include grass GE, EE, NDF, $\mathrm{ADF}$, and ash contents; in cases where all these variables are not available in practice, $\mathrm{EE}, \mathrm{NDF}$, and ADF may be excluded but this would compromise the prediction accuracy as implied by the higher MPE and standard error of the equations. Regarding ME predictions from grass nutrient concentrations, it should be noted that the explained variation for the prediction of ME concentrations and ME/GE ratio was lower compared with other predicted variables, but the standard errors and differences between predicted and actual variables were relatively low (less than 1.7 and $3.9 \%$ of the actual ME, respectively). Prediction of ME by using GE and ADF as explanatory variables in the equation may be recommended because it decreased prediction error compared with using N, EE, ADF, and ash as predictors.

When models of Givens et al. (1990b) to predict ME were validated against the same one-third of the data set used to validate equations developed in the current study, they showed higher MPE and standard error. However, both studies showed $\mathrm{R}^{2}<0.50$ for the prediction of ME only from grass nutrient contents; the correlations against the actual data used for the validation were very low. A higher error when predicting ME, than $\mathrm{DE}$, may be expected because it requires the evaluation of energy outputs in feces, urine, and methane, whereas predicting DE only requires evaluation of energy output in feces. Nutrient concentrations may be inefficient to accurately explain the additional energy losses in urine and methane possibly because these losses are also highly related to nutrient utilization, especially $\mathrm{N}$ and fiber, respectively (Hoekstra et al., 2007; Cottle et al., 2011). This implies the use of other explanatory variables, such as nutrient-digestibility parameters, may be essential to improve prediction accuracy of $\mathrm{ME}$ in equations that can be widely used under various pasture-based conditions.

\section{CONCLUSIONS}

Fresh grass is a cheap and common source of feed for cattle in temperate, cool, and moist areas in the world. Although fresh grass has a high variability of nutrient 
contents, expected to markedly affect its nutritive value, equations shown in the present study can efficiently relate nutrient digestibility and energy concentrations with chemical composition. This provides dairy and beef industry with a useful tool for rapid assessment of grass nutritive quality by using data that are routinely available to producers. The present equations may be used for cattle grazing in pure ryegrass swards and for various production stages (milking, weight gain, dry period) by applying feeding-level correction factors as described in existing feeding systems. Prediction equations in the current study have been developed by using a great range of grass quality, through different combinations of the most influential agronomic parameters (maturity stage, fertilization rates, harvest date, and grass variety) tested over $3 \mathrm{yr}$, so that they can be broadly applicable at farm level depending on the available chemical-composition data. Although the range of grass quality used may cover the majority of observed grass nutrient contents at commercial scale, all grass was grown within Agri-Food and Biosciences Institute Hillsborough; additional validation of these equations in future studies may further contribute to the decrease of the prediction error or the standardization of equations for grass from different geographical areas. Predictions of metabolizable energy showed relatively low standard error but also very low correlation with the actual values and lower prediction accuracy than the prediction of other variables, implying that using additional predictors, such as nutrient digestibility, may be necessary for its accurate evaluation.

\section{ACKNOWLEDGMENTS}

The authors gratefully acknowledge financial support from the Department of Agriculture, Food and the Marine of the Republic of Ireland under a Research Stimulus Fund Program (11/S/105) and the Department of Agriculture and Rural Development of Northern Ireland. We also thank colleagues at the Agri-Food and Biosciences Institute (Hillsborough, UK) for the collection of experimental data used in the present study. The authors declare no competing conflict of interest.

\section{REFERENCES}

Agnew, R. E., R. S. Park, C. S. Mayne, and A. S. Laidlaw. 2000. The potential of near infrared spectroscopy to predict the chemical and biological characteristics of grazed grass. Pages 51-52 in Grazing Management: The Principles and Practice of Grazing, for Profit and Environmental Gain, Within Temperate Grassland Systems. Proc. Br. Grassl. Soc. Conf., Harrogate. A. Rook and P. Penning, ed. Br. Grassl. Soc., Kenilworth, UK.

Agnew, R. E., T. Yan, J. France, E. Kebreab, and C. Thomas. 2004 Energy requirement and supply. Pages 11-20 in Feed into Milk:
A New Applied Feeding System for Dairy Cows. C. Thomas, ed. Nottingham Univ. Press, Nottingham, UK.

Cottle, D. J., J. V. Nolan, and S. G. Wiedemann. 2011. Ruminant enteric methane mitigation: A review. Anim. Prod. Sci. 51:491-514.

Dijkstra, J., O. Oenema, J. W. van Groenigen, J. W. Spek, A. M. van Vuuren, and A. Bannink. 2013. Diet effects on urine composition of cattle and N2O emissions. Animal 7(Suppl. 2):292-302.

Ferris, C. 2007. Sustainable pasture-based dairy systems-Meeting the challenges. Can. J. Plant Sci. 87:723-738.

Givens, D. I., J. M. Everington, and A. H. Adamson. 1989. The nutritive value of spring-grown herbage produced on farms throughout England and Wales over four years. I. The effect of stage of maturity and other factors on chemical composition, apparent digestibility and energy values measured in vivo. Anim. Feed Sci. Technol. 27:157-172.

Givens, D. I., J. M. Everington, and A. H. Adamson. 1990a. The nutritive value of spring-grown herbage produced on farms throughout England and Wales over four years. II. The prediction of apparent digestibility in vivo from various laboratory measurements. Anim. Feed Sci. Technol. 27:173-184.

Givens, D. I., J. M. Everington, and A. H. Adamson. 1990b. The nutritive value of spring-grown herbage produced on farms throughout England and Wales over four years. III. The prediction of energy values from various laboratory measurements. Anim. Feed Sci. Technol. 27:185-196.

Givens, D. I., A. R. Moss, and A. H. Adamson. 1993. Influence of growth stage and season on the energy value of fresh herbage. 2. Relationships between digestibility and metabolizable energy content and various laboratory measurements. Grass Forage Sci. $48: 175-180$.

Hoekstra, N. J., R. P. O. Schulte, P. C. Struik, and E. A. Lantinga. 2007. Pathways to improving the N efficiency of grazing bovines. Eur. J. Agron. 26:363-374.

Home Office. 1986. Animal (Scientific Procedures) Act 1986. Her Majesty's Stationery Off., London, UK.

Hopkins, A., and R. J. Wilkins. 2006. Temperate grassland: Key developments in the last century and future perspectives. J. Agric. Sci. 144:503-523.

Huhtanen, P., M. Rinne, and J. Nousiainen. 2009. A meta-analysis of feed digestion in dairy cows. 2. The effects of feeding level and diet composition on digestibility. J. Dairy Sci. 92:5031-5042.

VSN International. 2013. GenStat for Windows. 16th ed. VSN Int., Hemel Hempstead, UK.

Mayne, C. S., and F. J. Gordon. 1984. The effect of type of concentrate and level of concentrate feeding on milk production. Anim. Prod. 39:65-76.

McDonald, P., R. A. Edwards, J. F. D. Greenhalgh, and C. A. Morgan. 2002. Animal Nutrition. Pearson Educ. Ltd., Harlow, UK.

Miller, L. A., J. M. Moorby, D. R. Davies, M. O. Humphreys, N. D. Scollan, J. C. MacRae, and M. K. Theodorou. 2001. Increased concentration of water-soluble carbohydrate in perennial ryegrass (Lolium perenne L.): Milk production from late-lactation dairy cows. Grass Forage Sci. 56:383-394.

Morgan, D. J., and G. Stakelum. 1987. The prediction of the digestibility of herbage for dairy cows. Isr. J. Agric. Res. 26:23-34.

Mulvany, P. M. 1977. Dairy cow condition scoring. Paper No. 4468. Natl. Inst. Res. Dairying, Reading Univ., Reading, UK.

Nousiainen, J., M. Rinne, M. Hellamaki, and P. Huhtanen. 2003. Prediction of the digestibility of primary growth and regrowth grass silages from chemical composition, pepsin-cellulase solubility and indigestible cell wall content. Anim. Feed Sci. Technol. 110:61-74.

Nousiainen, J., M. Rinne, and P. Huhtanen. 2009. A meta-analysis of feed digestion in dairy cows. 1 . The effects of forage and concentrate factors on total diet digestibility. J. Dairy Sci. 92:5019-5030.

Phuong, H. N., N. C. Friggens, I. J. M. de Boer, and P. Schmidely. 2013. Factors affecting energy and nitrogen efficiency of dairy cows: A meta-analysis. J. Dairy Sci. 96:7245-7259.

Radojevic, I., R. J. Simpson, J. A. St. John, and M. O. Humphreys. 1994. Chemical composition and in vitro digestibility of lines of Lolium perenne selected for high concentrations of water-soluble carbohydrate. Aust. J. Agric. Res. 45:901-912. 
Robinson, D. L. 1987. Estimation and use of variance components. Statistician 36:3-14.

Searle, S. R., G. Casella, and C. E. McCulloch. 1992. Variance Components. Wiley, New York, NY.

Stergiadis, S., X. J. Cheng, M. Allen, D. Wills, and T. Yan. 2015. Evaluating nitrogen utilization efficiency of nonpregnant dry cows offered solely fresh cut grass at maintenance levels. J. Anim. Sci. 93:709-720. http://dx.doi.org/10.2527/jas.2014-8197.

Tas, B. 2006. Nitrogen utilization of perennial ryegrass in dairy cows. Pages 125-140 in Fresh Herbage for Dairy Cattle. A. Elgersma, J. Dijkstra, and S. Tamminga, ed. Springer, Wageningen, the Netherlands.

Waghorn, G. C., and D. A. Clark. 2004. Feeding value of pastures for ruminants. N. Z. Vet. J. 52:320-331.
Yan, T., and R. E. Agnew. 2004. Prediction of nutritive values in grass silages: I. Nutrient digestibility and energy concentrations using nutrient compositions and fermentation characteristics. J. Anim. Sci. $82: 1367-1379$

Yan, T., J. P. Frost, R. E. Agnew, R. C. Binnie, and C. S. Mayne. 2006. Relationships among manure nitrogen output and dietary and animal factors in lactating dairy cows. J. Dairy Sci. 89:3981-3991.

Yan, T., and C. S. Mayne. 2008. Prediction of methane emission of dairy cows offered fresh grass at maintenance level. Page 143 in Multifunctional Grasslands in a Changing World. Org. Comm. 2008 IGC/IRC Conf., ed. Guangdong People's Publ. House, China. 